\title{
Meningkatkan Kemampuan Koginitif Anak melalui Permainan Tebak Angka
}

\author{
Pujiningsih dan Subawi \\ Institut Pesantren Mathali'ul Falah Pati \\ Email: pujiningsih@gmail.com
}

\begin{abstract}
This research is to enhance cognitive abilities, especially the early childhood's ability to recognize numbers in playgroup Bina Bhakti Sari Purwosari Tlogowungu by using the number guessing game with plasticine or playdough props. Based on the cycle I and cycle II showing their improved cognitive ability in recognizing the concept of numbers in children KB Bina Bhakti Sari Purwosari Tlogowungu year 2016 / 2017. The average percentage increase in cognitive abilities in recognizing the concept of numbers of pre-cycle by $15 \%$, in the first cycle of $50 \%$, and the second cycle of $85 \%$. Thus the guessing game figures using playdough props can improve cognitive abilities in recognizing the concept of numbers in playgroup Bina Bhakti Sari Purwosari Tlogowungu Year 2016/2017, through the steps as follows: 1) Researchers prepare settings and props are used; 2) Researchers demonstrate game activities to be undertaken; 3) The researcher invites children to play guess the numbers to form the numbers using plasticine; 4) Researchers and child make conclusions about the results of the activities carried out; 5) Researchers are giving rewards to children who are able to do the activities well, and motivate children who have not been able to carry out activities.
\end{abstract}

Keywords: Cognitive Abilities, Number Guessing Game, Playdough. 


\section{PENDAHULUAN}

Pendidikan Anak Usia Dini adalah upaya pembinan yang ditujukan kepada anak sejak lahir sampai dengan usia 6 tahun yang dilakukan melalui pemberian rangsangan pendidikan, untuk membantu pertumbuhan dan perkembangan jasmani dan rohani agar anak memiliki kesiapan dalam memasuki pendidikan lebih lanjut (UU No. 20 Tahun 2003, Pasal 1, butir 14).Karena pada masa ini disebut dengan Golden Age dimana sel - sel otak anak berkembang sangat pesat, maka stimulasi pemberian rangsangan pendidikan sangat penting. Pertumbuhan dan perkembangan yang dimaksud antara lain mencakup aspek moral dan agama, fisik dan motorik, bahasa, kognitif, sosial emosional, dan seni. Yang mana aspek-aspek tersebut merupakan satu kesatuan yang saling terkait, yang mana dapat dirangsang secara seimbang sehingga anak dapat tumbuh secara optimal (Sumiati, 2011).

Pengembangan kemampuan kognitif dapat meningkatkan cara berfikir anak dan anak diharapkan mengenal konsep sains dan matematika sederhana. Dalam teori Piaget kognitif adalah kisah terpadu yang menjelaskan bagaimana faktor biologis dan pengalaman membentuk perkembangan kognitif, Piaget berpikif sebagaimana tubuh fisik kita memiliki struktur yang memampukan kita beradaptasi dengan dunia, dan Piaget menekankan bahwa anak - anak secara aktif membangun dunia - dunia kognitif mereka sendiri (Jhon. W. Santrock, 2007). Diharapkan pada pengembangan kognitif ini anak dapat mengenal bilangan angka dengan baik. Maka dalam kegiatan pembelajaran guru dapat menggunakan media permainan sehingga anak merasa tertarik dan akan mudah memahami apa yang diajarkan.

Berdasarkan pengamatan yang dilakukan peneliti di KB Bina Bhakti Sari ditemukan masih rendah dan kurang dalam mengenal konsep bilangan karena dalam mengajarkan guru hanya menggunakan metode ceramah. Disini guru yang lebih dominan menguasai kelas sesudah memberikan konsep bilangan melalui metode ceramah guru langsung memberikan tugas, tanpa memberikan pilihan kegiatan lain kepada anak. Karena anak butuh bermain, karena mereka membutuhkan pengalaman langsung dalam interaksi sosial agar mereka memperoleh dasar kehidupan social (Tadkiroatun Musfiroh, 2008). Dan guru kurang memanfaatkan media pembelajaran dan permainan yang tepat sehingga anak menjadi kurang tertarik dan sulit memahami konsep bilangan yang diajarkan. 
Menilik pada permasalahan di atas guru mengganti metode pembelajarannya, yang awalnya menggunakan metode ceramah diganti dengan menggunakan metode permainan tebak angka dan memanfaatkan media Alat Peraga yang menarik. Guru menggunakan plastisin untuk bermain tebak angka, karena anak akan membuat angka dengan menggunakan plastisin itu. Dengan demikian diharapkan pengenalan konsep bilangan pada siswa KB Bina Bhakti Sari dapat meningkat dan anak menjadi mudah mengingat konsep bilangan yang telah diajarkan dengan metode permainan tadi. Karena dengan menggunakan permainan tebak angka selain anak belajar konsep bilangan anak juga bermain sehingga dalam pembelajaran yang berlangsung anak menjadi senang dan tidak bosan.

\section{METODE}

Penelitian ini adalah penelitian tindakan kelas, metode yang digunakan adalah dengan melakukan tindakan. Penelitian ini dilaksanakan di KB Bina Bhakti Sari Desa Purwoari Kecamatan Tlogowungu Kabupaten Pati Tahun Pelajaran 2016 - 2017. Penelitian ini direncanakan dilaksanakan pada tahun 2016/2017. Dan dilaksanakan pada bulan November 2016 Pebruari 2017.

Subyek dalam penelitian ini adalah siswa KB Bina Bhakti Sari Kecamatan Tlogowungu Kabupaten Pati Tahun Pelajaran 2016/2017 dengan jumlah siswa 20 orang, anak laki - laki 5 orang anak perempuan 15 orang. Sumber data dalam penelitian ini yaitu, Data primer adalah data penelitian yang bersumber dari anak didik yang dijadikan subyek langsung dalam penelitian. Data ini berasal dari pengamatan Wawancara maupun hasil kerja yang dicatat oleh peneliti, serta Data sekunder adalah data penelitian yang berupa data pendukung yang diperoleh dari sekolah, panduan akademik dan data hasil pengamatan yang dilakukan oleh teman sejawat.

Teknik pengumpulan data adalah data yang dikumpulkan melalui cara nontulis, data ini terdiri dari data wawancara dan observasi / pengamatan. Data yang peneliti peroleh dari dokeumen wawancara yang ada adalah mengenai: Sejarah berdirinya KB Bina Bhakti Sari, Struktrur organisasi KB Bina Bhakti Sari, Jumlah anak didik yang ada di KB Bina Bhakti Sari, Data guru KB Bina Bhakti Sari, Sarana dan Prasarana KB 
Bina Bhakti Sari, Foto - foto di KB Bina Bhakti Sari. Observasi yang dilakukan peneliti dengan melakukan pengamatan dan mencatat apa yang terjadi untuk mengamati bagaimana perkembangan kognitif yang terjadi di KB Bina Bhakti Sari. Teknik dokumentasi ini juga digunakan untuk mencari data tentang struktur, karyawan, jumlah sarana dan prasarana di KB Bina Bhakti Sari Purwosari dan data - data lain yang dapat membantu dalam penelitian.

\section{HASIL PENELITIAN}

Pada kondisi awal di KB Bina Bhakti Sari Purwosari mengenai kemampuan kognitif khususnya dalam mengenai bilangan masih sangat rendah dan perlu ditingkatkan. Ini dikarenakan guru dalam mengajarkan kognitif mengenalkan bilangan hanya menggunakan metode ceramah setelah itu guru langsung memberikan tugas, tanpa memberikan pilihan kegiatan lain kepada anak. Sedangkan anak sangat membutuhkan kegiatan yang menarik dengan kegiatan dengan dilakukan dengan bermain. Melihat kondisi diatas maka guru cara mengajar yang awalnya dengan metode ceramah diganti dengan menggunakan metode permainan. Permainan yang digunakan untuk meningkatkan kognitif dalam mengenal bilangan adalah permainan tebak angka dengan mengunakan alat peraga untuk melakukan permainan ini yaitu dengan menggunakan plastisin, dimana plastisin ini sangat mudah dibentuk, bahannya aman dan sangat menarik karena berwarna-warni jenisnya.

Permainan ini diharapkan meningkatnya kemampuan kognitif anak tentang mengenal bilangan. Karena anak akan bermain sambil belajar dalam kegiatan ini. Maka peneliti akan menggunakan dua siklus dalam menerapkan permainan ini yaitu siklus I dan siklus II.

Tabel 1.

Hasil Penelitian pra siklus Kegiatan Pembelajaran Kemampuan Kognitif Anak di KB Bina Bhakti Sari

\begin{tabular}{|l|l|c|c|c|c|}
\hline \multicolumn{1}{|c|}{ Aspek } & Indikator & Nilai & $\begin{array}{c}\text { Jumlah } \\
\text { anak }\end{array}$ & Presentase & Keterangan \\
\hline Kognitif & Mengenal & A & - & - & Sangat Baik \\
& bilangan & B & 3 & $15 \%$ & Baik \\
& angka & C & 5 & $25 \%$ & Cukup \\
& & D & 12 & $60 \%$ & Kurang \\
\hline \multicolumn{7}{|l}{ Jumlah } & 20 & $100 \%$ & \\
\hline
\end{tabular}


Dari hasil tabel dan grafik di atas dapat diperoleh data bahwa kemampuan kognitif anak KB Bina Bhakti Sari adalah sebagai berikut:
A. (Sangat Baik)
$=0 \%$
B. (Baik)
$=15 \%$
C. (Cukup)
$=25 \%$
D. (Kurang)
$=60 \%$

Berdasarkan tabel di atas dapat diketahui bahwa kemampuan kognitif anak dalam mengenal bilangan sangat rendah, karena dari 20 anak yang mengenal bilangan dengan baik cuma 3 anak sehingga perlu diadakan tindakan lebih lanjut.

Pada siklus I ini peneliti menfokuskan meningkatkan kemampuan kognitif mengenal bilangan melalui permainan tebak angka dengan menggunakan demontrasi di papan tulis dan plastisin. Adapun kegiatan yang dilakukan selam proses pembelajaran pada siklus I yang meliputi tahap perencanaan, pelaksanaan, pengamatan dan refleksi di uraikan sebagai berikut:

\section{Perencanaan}

Pada siklus I, perencanaan penelitian tindakan kelas dimulai dari penyusunan rncana kegiatan harian (RKH), dimana kegiatan yang dilakukan khusus tentang meningkatkan kemampuan kognitif melalui permainan tebak angka yang memfokuskan pada pengenalan bilangan. Kemudian guru menyiapkan peralatan yang akan digunakan dalam proses pembelajaran yaitu spidol, papan tulis, plastisin. Semua benda disiapkan ini semua agar dalam proses pembelajaran berjalan dengan baik dan anak-anak dapat mengikuti dengan senang.

\section{Pelaksanaan}

Tindakan pada siklus I ini dilakukan pembelajaran dengan pendekatan konseptual dalam kelompok besar karena jumlah anak KB Bina Bhakti Sari berjumlah 20 anak, maka dibagi menjadi 2 kelompok masing-masing kelompok berjumlah 10 anak. Masing-masing kelompok akan didatangi guru dan disuruh menebak angka berapa itu.Pembelajaran yang dilaksanakan terdapat; Kegiatan Awal, peneliti mengajak anakanak berbaris didepan kelas dengan menyanyikan lagu masuk kelas, kemudian berhitung satu persatu untuk masuk kelas, Sebelum berdoa menyanyikan lagu anak sholeh, Peneliti mengajak anak-anak berdoa, Peneliti mengkondisikan kelas mengajak anak-anak bernyanyi dan menggerakkan tubuh 
supaya anak-anak semangat, Peneliti mengabsen anak satu persatu, Peneliti melakukan apersepsi sesuai dengan RKH yang sudah ada; Kegiatan Inti, Peneliti membagi anak menjadi dua kelompok masing-masing kelompok terdiri dari 10 anak; Kegiatan Akhir, Peneliti mengulang kegiatan inti dengan mengenal bilangan dengan menulis angka di papan tulis anakanak disuruh menebak, berdoa mau pulang, pesan kepada anak sebelum pulang, Kemudian salam dan pulang.

\section{Pengamatan}

Berdasarkan hasil observasi yang sudah dilakukan, maka dapat diketahui bagaimana kegiatan meningkatkan kemampuan kognitif melalui permainan tebak angka di KB Bina Bhakti Sari ini mengalami peningkatan dari 20 anak yang 3 anak sangat baik, 7 anak baik, 6 anak cukup, 4 anak kurang.

Tabel 2.

Hasil Penelitian Siklus I Kegiatan Pembelajaran Kemampuan Kognitif Anak di KB Bina Bhakti Sari

\begin{tabular}{|c|c|c|c|c|c|}
\hline Aspek & Indikator & Nilai & $\begin{array}{c}\text { Jumlah } \\
\text { anak }\end{array}$ & Presentase & Keterangan \\
\hline Kognitif & Mengenal & A & 3 & $15 \%$ & Sangat Baik \\
& bilangan & B & 7 & $35 \%$ & Baik \\
& angka & C & 6 & $30 \%$ & Cukup \\
& & D & 4 & $20 \%$ & Kurang \\
\hline & Jumlah & 20 & $100 \%$ & \\
\hline
\end{tabular}

Berdasarkan tabel di atas dapat diketahui bahwa terdapat peningkatan pada siklus I dibanding dengan pra siklus. Ada $15 \%$ anak yang sudah termasuk kategori sangat baik, 35\% termasuk kategori baik, 30\% termasuk kategori cukup dan $20 \%$ termasuk kategori kurang. Aktifitas guru masih memerlukan perbaikan dipertemuan berikutnya adalah dalam memberikan penjelasan kegiatan permainan tebak angka masih kurang terinci dan saat mendemontrasikan intonasi suara kurang sedikit keras sehingga anak kurang memperhatikan dengan detail, anak hanya tertarik sama media saja dan kurang jelas tentang pelaksanaan kegiatan yang dijelaskan. Adapun aktivitas anak yang masih memerlukan perbaikan dipertemuan berikutnya adalah anak malah asik sendiri dengan media yang disediakan dengan membuat mainan sendiri dengan plastisin ini. 


\section{Refleksi}

Meskipun dalam perbaikan siklus I ini mengalami peningkatan presentas, tetapi hasil yang telah diperoleh belum memenuhi target indikator keberhasilan yang ditentukan. Selain itu, masih banyak kekurangan dan perlu diadakannya perbaikan. Oleh karena itu, peneliti mengadakan perbaikan kembali pada siklus II. Kegiatan yang dilakukan juga harus lebih menarik dari kegiatan sebelumnya. Jika siklus I dilakukan secara kelompok besar dan anak kurang fokus, maka pada siklus II nanti kegiatan yang dilakukan anak adalah mengenal bilangan dengan bermain tebak angka dalam kelompok kecil supaya anak lebih mudah menerima pembelajaran.

Adapun kegiatan yang dilakukan selam proses pembelajaran pada siklus II yang meliputi tahap perencanaan, pelaksanaan, pengamatan dan refleksi diuraikan sebagai berikut:

\section{Perencanaan}

Pada siklus II, perencanaan penelitian tindakan kelas dimulai dari penyusunan rncana kegiatan harian $(\mathrm{RKH})$, dimana kegiatan yang dilakukan khusus tentang meningkatkan kemampuan kognitif melalui permainan tebak angka yang memfokuskan pada pengenalan bilangan. Kemudian guru menyiapakan peralatan yang akan digunakan dalam proses pembelajaran.

\section{Pelaksanaan}

Tindakan pada siklus II ini dilakukan pembelajaran dengan pendekatan konseptual dalam kelompok kecil karena jumlah anak KB Bina Bhakti Sari berjumlah 20 anak, maka dibagi menjadi 4 kelompok masing-masing kelompok berjumlah 5 anak. Pembelajaran yang dilaksanakan terdapat; Kegiatan Awal, peneliti mengajak anak-anak berbaris didepan kelas dengan menyanyikan lagu masuk kelas, kemudian berhitung satu persatu untuk masuk kelas, Sebelum berdoa menyanyikan lagu anak sholeh, Peneliti mengajak anak-anak berdoa, Peneliti mengkondisikan kelas mengajak anak-anak bernyanyi dan menggerakkan tubuh supaya anak-anak semangat, Peneliti mengabsen anak satu persatu, Peneliti melakukan apersepsi sesuai dengan RKH yang sudah ada; Kegiatan Inti, Peneliti membagi anak menjadi dua kelompok menjadi 4 kelompok masing-masing kelompok terdiri dari 5 orang.; Kegiatan Akhir, Peneliti mengulang kegiatan inti dengan mengenal bilangan dengan menulis angka di papan tulis anak-anak disuruh menebak, berdoa mau pulang, pesan kepada anak sebelum pulang, Kemudian salam dan pulang. 
3. Pengamatan

Berdasarkan hasil observasi yang sudah dilakukan, maka dapat diketahui bagaimana kegiatan meningkatkan kemampuan kognitif melalui permainan tebak angka di KB Bina Bhakti Sari ini mengalami peningkatan dari 20 anak yang dapat mengikuti kegiatan permainan tebak angka ada 7 anak dikategorikan sangat baik, 10 anak dikaregorikan baik, dan 3 anak dikaregorikan cukup.

Tabel 3.

Hasil Penelitian Siklus II Kegiatan Pembelajaran Kemampuan Kognitif Anak di KB Bina Bhakti Sari

\begin{tabular}{|c|c|c|c|c|c|}
\hline Aspek & Indikator & Nilai & $\begin{array}{c}\text { Jumlah } \\
\text { anak }\end{array}$ & Presentase & Keterangan \\
\hline Kognitif & Mengenal & A & 7 & $35 \%$ & Sangat Baik \\
& bilangan & B & 10 & $50 \%$ & Baik \\
& angka & C & 3 & $15 \%$ & Cukup \\
& & D & 0 & $0 \%$ & Kurang \\
\hline & Jumlah & 20 & $100 \%$ & \\
\hline
\end{tabular}

Berdasarkan tabel di atas dapat diketahui bahwa hanya 85\% anak yang sudah termasuk kategori baik dan 15\% termasuk dalam kategori cukup. Menurut analisis yang dilakukan oleh peneliti dari data observassi kegiatan siklus II, hasil yang telah diperoleh sudah memenuhi target indicator keberhasilan yang telah ditentukan, yakni $80 \%$

\section{Refleksi}

Berdasarkan hasil penelitian, dalam melaksanakan pembelajaran pada siklus II yang dilakukan dalam dua pertemuan dapat diketahui bahwa ada peningkatan pada hasil pembelajaran peningkatan kemampuan kognitif melalui permainan tebak angka di banding siklus I. Dari data hasil observasi dari data hasil belajar anak pada akhir pelaksanaan perbaikan pembelajaran dapat disimpulkan bahwa pelaksanaan perbaikan pasa siklus II berjalan dengan baik. Dalam hal ini antara guru dan hasil belajar anak memuaskan yaitu $90 \%$. Sehingga indikator keberhasilan yang telah ditentukan tercapai.

\section{PEMBAHASAN}

Dalam kondisi awal sebelum pelaksanan tindakan, menyatakan bahwa tingkat kemampuatn kognitif anak masih 
rendah. Hal tersebut dikarenakan guru masih jarang melakukan kegiatan dengan menggunakan media pembelajaran. Selama ini guru hanya menggunakan lembar kerja anak hasilnya kurang faham tentang konsep pengenalan bilangan.

Penelitian ini dilaksanakan dalam 2 siklus, yaitu siklus I dan siklus II. Masing-masing siklus terdiri dari perencanaan, tindakan dan pengamatan serta refleksi. Siklus II merupakan perbaikan siklus I. Dari penelitian tersebut terjadi peningkatan kemampuan kognitif anak.

Pada siklus I, guru membagi anak dalam kelompok besar, dimana 20 anak dibagi menjadi 2 kelompok yang masingmasing kelompok terdiri dari 10 anak. Saat kegiatan berlangsung kemampuan kognitif melalui permainan tebak angka pada anak meningkat, misal sudah ada beberapa anak yang dapat mengikuti pembelajaran bermain tebak angka yang menggunakan plastisin membentuk pola bilangan. Terbukti pada siklus I setelah anak melakukan kegiatan kognitif mengenal bilangan melalui permainan tebak angka mengalami peningkatan dibandingkan pada prasiklus. Hasil yang diperoleh pada siklus I adalah $50 \%$.

Setelah siklus I kemudian dilakukan refleksi. Refleksi dilakukan oleh peneliti dan kolaborasi dengan teman sejawat untuk membahas tentang kekurangan untuk diperbaikin pada siklus II nanti. Karena hasil yang didapat pada siklus I belum memenuhi indicator keberhasilan, maka peneliti mengadakan siklus II.

Pada siklus II,peneliti membuat kelompok kecil dari 20 anak dibagi menjadi 4 kelompok setiap kelompok terdiri dari 5 anak. Setelah diadakan perbaikan pembelajaran pada siklus II ini, kemampuan kognitif anak semakin meningkat dibandingkan pras siklus dan siklus I. hasil yang diperoleh pada siklus II adalah $85 \%$ angka yang dicapai telah melibihi target indikator yang telah ditetapkan dan dinyatakan bahwa kemampuan kognitif anak di KB Bina Bhakti Sari Purwosari sudah meningkat sangat pesat.

Berdasarkan pengamatan dari siklus I dan siklus || dapat disimpulkan bahwa permainan tebak angka dapat meningkatkan kemampuan kognitif pada anak di KB Bina Bhakti Sari Purwosari Tahun Ajaran 2016/2017. 


\section{SIMPULAN}

Pada kondisi awal sebelum pelaksanaan tindakan dinyatakan bahwa tingkat kemampuan kognitif anak masih sangat rendah yakni hanya mencapai $15 \%$. Dengan tindakannya kegiatan permainan tebak angka yang menggunakan media plastisin pada siklus I kemampuan kognitif anak mengalami peningkatan dibandingkan pada pra siklus. Hasil yang diperoleh pada siklus I adalah $50 \%$ dan pada siklus II meningkat menjadi $85 \%$. Pada siklus II hasil yang dicapai telah melebihi target indicator yang telah ditetapkan dan dinyatakan bahwa kemampuan kognitif anak KB Bina Bhakti Sari Purwosari tahun ajaran 2016/2017 sudah meningkat pesat.

Berdasarkan pengamatan dari siklus I dan siklus || dapat disimpulkan bahwa kegiatan permainan tebak angka dapat meningkatkan kemampuan kognitif pada anak di KB Bina Bhakti Sari Purwosari Tahun Ajaran 2016/2017.

\section{REFERENSI}

Durri Andriani, dkk, Metode Penelitian, Tangerang Selatang, Universitas Terbuka, 2012

Elizabeth B Hurlock, Perkembangan Anak Jilid 1, Jakarta, Erlangga, 1997

Jhon. W. Santrok, Perkembangan Anak, University of Texas, Dallas, 2007

Markamah, "Upaya meningkatkan Kemampuan Kognitif Melalui Penggunaan Media Dadu Angka Pada Anak Kelompok B TK Pertiwi 2 Sobokerto Ngemplak Boyolali Tahun Pelajaran 2013-2014", Surakarta, UMS, 2014

Ninik Novita Sari, "Penggunaan Media Pohon Hitung Untuk Meningkatkan Kemampuan Kognitif Anak Kelompok B TK PKK 1 Ngadirejo Kecamatan Kepanjen Kidul Kota Blitar", Ubaya, 2014

Rahman Hibana S., Konsep Dasar Pendidikan Anak Usia Dini. Yogyakarta, PGTK Press, 2005

Suhartin, "Meningkatkan Kemampuan Mengenal Huruf dan Angka Melalui Permainan Tebak Huruf dan Angka Pada Anak Kelompok B TK Kusumah Mulia Tahun Pelajaran 2014/2015", (Kediri, UNP PGRI Kediri, 2015 
Meningkatkan Kemampuan Koginitif Anak melalui Permainan Tebak Angka

Sumiati, PAUD Inklusi PAUD Masa Depan, Yogyakarta. Cakrawala Institute, 2011

Tadkiroatun Musfiroh, Cerdas Melalui Bermain Bersama, Jakarta, Grasindo, 2008

UU No. 20 Tahun 2003, Pasal 1, butir 14

Wina Sanjaya, Penelitian Tindakan Kelas, Jakarta, Kencana Prenada Media Group, 2009.

Gibson, Pengertian Kemampuan Menurut Definisi Para Ahli, http://www.landasanteori.com /2015/10/ pengertiankemampuan-menurut-definisi.html diakses pada tanggal 7 Desember 2016 jam 12.15

Depdiknas, Pengertian kemampuan kognitif, http://pembelajaran-pendidikan.blogspot.co.id/2012/ 04/pengertian-kemampuan-kognitif.html diakses pada tanggal 7 Desember 2016 Jam 13.10 
Pujiningsih dan Subawi

120 | AL HIKMAH: INDONESIAN JOURNAL OF EARLY CHILDHOOD ISLAMIC EDUCATION | VOL.1 (1) 2017 